\title{
ACESSIBILIDADE EM MUSEUS: \\ IDEIAS E PRÁTICAS EM CONSTRUÇÃO
}

\author{
MUSEUM ACCESSIBILITY: \\ IDEAS AND PRACTICES UNDER CONSTRUCTION
}

\section{ACCESIBILIDAD EN MUSEOS: IDEAS Y PRÁCTICAS EN CONSTRUCCIÓN}

Gabriela Aidar $^{2}$

\begin{abstract}
RESUMO
O texto apresenta e problematiza diferentes pontos de vista a respeito da acessibilidade em museus. Usualmente entendido como sinônimo de ações voltadas a pessoas com deficiência, a acessibilidade possibilita outros olhares a coletivos com dificuldades de acesso. São discutidas ainda questões relativas à inclusão e desenvolvimento de públicos nas instituições museológicas e compartilhados exemplos de projetos de acessibilidade da Pinacoteca de São Paulo, do Museo Nacional de Colombia e do Montreal Museum of Fine Arts.
\end{abstract}

PALAVRAS-CHAVE: acessibilidade, inclusão, desenvolvimento de públicos, educação museal.

\begin{abstract}
The text presents and problematizes different points of view regarding accessibility in museums. Usually understood as synonymous of actions aimed at people with disabilities, accessibility makes possible diverse approaches aimed at groups with access difficulties. It also discusses issues related to inclusion and audience development in museums and shares examples of accessibility projects of the Pinacoteca de São Paulo, the Museo Nacional de Colombia and the Montreal Museum of Fine Arts.
\end{abstract}

KEYWORDS: accessibility, inclusion, audience development, museum education.

\section{RESUMEN}

El texto presenta y problematiza diferentes puntos de vista acerca de la accesibilidad en museos. Usualmente entendido como sinónimo de acciones dirigidas a personas con discapacidad, la

Submetido em: 14/03/2017 - Aceito em: 08/06/2017 - Publicado em: 04/07/2017. [NÃO PREENCHER]

${ }^{2}$ Graduada em História pela Universidade de São Paulo (USP), especialista em Estudos de Museus de Arte pelo Museu de Arte Contemporânea e em Museologia pelo Museu de Arqueologia e Etnologia, ambos da USP. Obteve o título de Master of Arts in Museum Studies pela Universidade de Leicester, no Reino Unido. Trabalha desde 2002 no Núcleo de Ação Educativa da Pinacoteca de São Paulo onde coordena os Programas Educativos Inclusivos. 


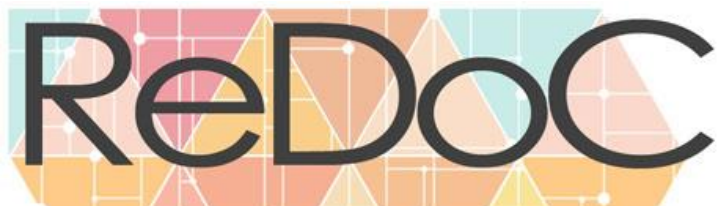

\section{Revista Docência e Cibercultura}

accesibilidad posibilita otras miradas a colectivos con dificultades de acceso. Se discutirán también cuestiones relativas a la inclusión y formación de públicos en las instituciones museológicas y serán compartidos ejemplos de proyectos de accesibilidad de la Pinacoteca de São Paulo, del Museo Nacional de Colombia y del Montreal Museum of Fine Arts.

PALABRAS CLAVE: accesibilidad, inclusión, formación de públicos, educación museal.

A tarefa de construir e compartilhar uma reflexão sobre a acessibilidade em museus, proposta pelas organizadoras deste dossiê, levou-me a rever minha produção sobre o tema, bem como a de colegas, e buscar novas referências para atualizar o debate. Atuo na mesma instituição museológica - a Pinacoteca de São Paulo - desde 2002, sempre na Área de Ação Educativa, e, ainda que em diferentes funções, com uma prática constantemente ligada ao desenvolvimento de projetos e programas educativos que poderíamos denominar como acessíveis. Ou seja, a questão da acessibilidade em museus é algo com que lido cotidianamente em minha trajetória profissional. Assim, o que pretendo com este texto, além de compartilhar minha experiência e reflexões, é problematizar alguns pontos relativos ao tema e à sua utilização na prática dos museus.

Da mesma forma como acontece com outros conceitos da área museológica, o termo “acessibilidade em museus" não é consensual. Sua definição e utilização dependem de opções ideológicas, metodológicas, e de referências bibliográficas particulares. No âmbito museológico brasileiro, assim como no internacional, o uso do termo "acessibilidade" é inicialmente compreendido como sinônimo de ações para pessoas com deficiência. A estreita relação dos museus com as escolas e o seu uso pela educação formal - há mais tempo do que pelas instituições culturais, aliás - talvez sejam os responsáveis por essa associação.

A inclusão de pessoas com deficiência nas escolas ganhou força a partir dos anos 1960 em países europeus, o que levou as instituições de educação formal a adaptarem suas abordagens educativas para as necessidades das crianças e jovens com deficiência (OLIVEIRA, 2015, p. 76). Um marco nesse processo dá-se com a "Declaração de Salamanca sobre Princípios, Políticas e Práticas na Área das Necessidades Educativas Especiais”, de 1994, a qual recomenda que a educação de pessoas com necessidades educacionais especiais faça parte do sistema regular de ensino, por meio do preparo e adaptação das próprias escolas. De acordo com o documento, a educação para essas pessoas deve considerar o processo de aprendizagem adaptado às necessidades do educando, ao invés de tentar acomodar as crianças e os jovens às lógicas preconcebidas da escola a respeito da aprendizagem. É interessante notar como o documento entende as chamadas necessidades educacionais especiais, originadas a partir de 


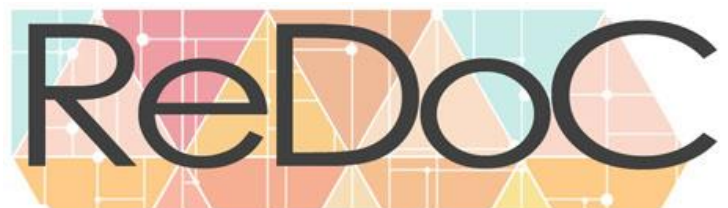

\section{Revista Docência e Cibercultura}

deficiências ou dificuldades de aprendizagem. Citando o item 3 do "Marco de Acción sobre Necesidades Educativas Especiales",

El principio rector de este Marco de Acción es que las escuelas deben acoger a todos los niños, independientemente de sus condiciones físicas, intelectuales, sociales, emocionales, lingüísticas u otras. Deben acoger a niños discapacitados y niños bien dotados, a niños que viven en la calle y que trabajan, niños de poblaciones remotas o nómadas, niños de minorías lingüísticas, étnicas o culturales y niños de otros grupos o zonas desfavorecidos o marginados. (UNESCO, 1994, p. 6)

Assim, é elucidativo perceber que a compreensão dos grupos excluídos em um documento referencial para a área da educação inclusiva abarque diversas necessidades e grupos, além daqueles com deficiência.

No senso comum da educação formal no Brasil, entretanto, os termos "acessibilidade" e "inclusão" se referem especificamente a ações voltadas a pessoas com deficiência. Mas como lidamos com essas questões em nossa prática nos museus? Essa relação é tão direta e inequívoca?

\section{Acessibilidade, inclusão e desenvolvimento de públicos}

Ainda que a acessibilidade em museus seja um tema transversal a toda a instituição, vou discuti-la neste artigo principalmente do ponto de vista da educação. Nesse sentido, o uso do termo é recorrente entre os profissionais da área, de distintas formas. Em 2015, o Comitê de Educação e Ação Cultural do Conselho Internacional de Museus (CECA/ICOM) organizou sua 46 conferência anual com o tema "Museum Education and Accessibility: Bridging the Gaps" ("Educação em museus e acessibilidade: ultrapassando as diferenças"), em Washington, nos Estados Unidos. Participaram profissionais de museus, em sua maioria educadores, de 31 países, o que nos propicia um interessante panorama do uso do termo em distintos contextos. ${ }^{3}$ Nos anais do evento encontram-se os resumos das apresentações, que abordam experiências educativas, estudos de caso, pesquisas e reflexões sobre a acessibilidade em museus, tendo como públicos-alvo especialmente pessoas com deficiência, mas também crianças, jovens, pessoas com 60 anos ou mais, famílias, grupos comunitários, grupos em situação de vulnerabilidade social, imigrantes, pessoas privadas de liberdade, grupos LGBTI e pacientes de hospitais, entre outros. Ainda é possível notar a relação que fazem alguns profissionais de

\footnotetext{
${ }^{3}$ Participaram profissionais dos seguintes países: Armênia, Bélgica, Brasil, Canadá, Chile, Cingapura, Croácia, Dinamarca, Equador, Espanha, EUA, Finlândia, Geórgia, Grécia, Holanda, Irlanda, Itália, Japão, Lituânia, Malaui, México, Peru, Portugal, Quênia, Reino Unido, Rússia, Suécia, Taiwan, Tanzânia, Turquia e Uzbequistão.
} 


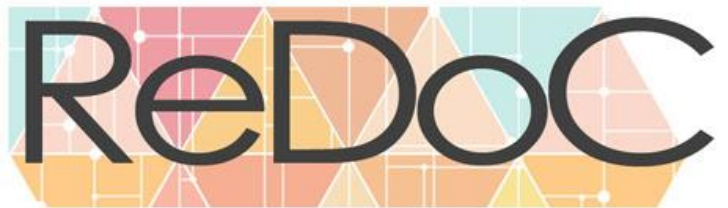

\section{Revista Docência e Cibercultura}

países do Hemisfério Norte entre a acessibilidade e a participação em museus e as novas tecnologias e redes sociais como ferramentas que possibilitam o acesso a diferentes públicos (MONACO, 2016).

A variedade de públicos-alvo e abordagens compartilhados nesse encontro nos indica a diversidade do uso e da compreensão sobre o termo. Nas memórias do encontro, assim como em publicações recentes de âmbito nacional e internacional, pode-se ver a presença de outros termos e conceitos que aparecem recorrentemente associados ao de acessibilidade, entre eles alteridade, autonomia, cidadania, diversidade, emancipação, equidade, identidade, mobilidade, participação e, por fim, inclusão (SESC-SP, 2018; ARGENTINA, 2018; AAM, 2019). Este último é o mais recorrente, sendo muitas vezes utilizado como sinônimo de acessibilidade assim, vale a pena nos determos nele.

Se nos basearmos na definição de exclusão social como um processo e um estado pelos quais dinâmicas sociais e instituições impedem a indivíduos e grupos uma ampla participação na sociedade, será possível argumentar que os museus podem desempenhar um papel numa rede de elementos excludentes ou, por oposição, podem ser ferramentas para a inclusão. Além do mais, dada a natureza multidimensional da exclusão (envolvendo questões como a falta de participação política, social e cultural, de acesso a mercados de trabalho e de redes de sociabilidade), políticas que busquem a inclusão invariavelmente assumirão uma abordagem interdisciplinar. Isso coloca as instituições culturais na arena dos problemas sociais, apenas aparentemente alheios às suas atribuições, uma vez que não é possível desvincular a ação cultural de uma ação social (AIDAR, 2002). Dessa forma, a pretensa neutralidade das instituições culturais cai por terra, o que leva alguns autores a afirmar que qualquer organização cultural que não esteja trabalhando para romper as barreiras com relação aos grupos socialmente excluídos está ativamente mantendo-as (O’NEILL, 2002, p. 37). Segundo esse autor,

O conceito de inclusão social significa buscar ativamente remover as barreiras, reconhecendo que pessoas que foram apartadas por gerações precisam de apoio adicional numa ampla variedade de formas, de modo a permitir que possam exercer seu direito de participação em muitas das oportunidades que os privilegiados e escolarizados têm garantidas. (O’NEILL, 2002, p. 34, tradução minha)

Outra questão que gera dúvidas dentro do binômio inclusão/acessibilidade é a do desenvolvimento de públicos, que costuma ser também visto ou como sinônimo dos dois outros termos, ou como complementar a eles. O desenvolvimento de públicos pode ser entendido como a identificação das diferentes barreiras que acabam por excluir indivíduos ou grupos da frequência aos museus, e a posterior elaboração de estratégias que superem essas barreiras, trazendo para os museus públicos tradicionalmente não visitantes. 
Processos inclusivos deveriam propor, para além de um maior acesso às instituições museológicas, o desenvolvimento de ações que tenham impacto político, social e econômico, e que podem ter alcance tanto a curto quanto a longo prazo (AIDAR, 2002, p. 59-60). Daí a relação mais estreita entre os processos inclusivos e a educação museal, já que ambos buscam promover impactos de ordem qualitativa no cotidiano de seus participantes. Além do mais, enquanto podemos ver o desenvolvimento de públicos como algo que beneficie primeiramente a instituição - ao aumentar seus números de visitação e diversificar o perfil de seus usuários , as ações inclusivas focam nos benefícios que o contato com o museu pode promover em seus públicos, independentemente até mesmo de sua posterior fidelização, que deve ser uma decorrência e não o objetivo principal das ações.

Após estes apontamentos, é relevante, portanto, perguntar: quem são os excluídos dos museus brasileiros? Algumas pesquisas de público feitas nos últimos 15 anos no país nos ajudam a delinear uma resposta a essa questão. ${ }^{4}$ De acordo com investigação sobre hábitos culturais realizada em 2017 em 12 capitais brasileiras, no que diz respeito aos museus, pode-se caracterizar um perfil de visitantes composto por pessoas jovens (mais da metade com até 34 anos), com predominância pouco maior de homens, com alta escolaridade (57\% com ensino superior) e renda (62\% na classe A). O mesmo estudo aponta o perfil de quem afirmou nunca ter visitado um museu em sua vida: pessoas com baixa escolaridade - quase metade delas com ensino fundamental (49\%), e em sua maioria das classes D/E (55\%) (LEIVA; MEIRELLES, 2018). Ou seja, o perfil de visitantes e de não visitantes de museus representa dois extremos das classes sociais do país, como os lados opostos de uma mesma moeda.

Como afirma ainda a mesma pesquisa, as classes $\mathrm{C}$ e D/E são as que abrigam a maior parte da população brasileira, assim, no caso específico dos museus, os indivíduos e grupos excluídos não pertencem às chamadas minorias, como acontece em países mais ricos, ao menos não a minorias populacionais, mas ao que podemos chamar de minorias políticas ou culturais.

Se os dados referentes aos públicos excluídos dos museus brasileiros são assim evidentes, por que parte de seus profissionais seguem desenvolvendo ações inclusivas ou de acessibilidade exclusivamente para pessoas com deficiência? Essa não é uma questão que comporte uma resposta única ou objetiva, mas podemos aqui levantar uma hipótese. A divisão de classes da sociedade brasileira, com sua lógica classista e seu preconceito de classe, talvez

\footnotetext{
${ }^{4}$ Além das pesquisas citadas neste texto, podemos mencionar: Silva, Frederico. Economia e política cultural: acesso, emprego e financiamento. Brasília: Ministério da Cultura, 2007. v. 3 (Coleção Cadernos de Políticas Culturais). Köptcke, Luciana; Cazelli, Sibele; Lima, José. Museus e seus visitantes: relatório de pesquisa perfilopinião 2005. Brasília: Gráf. e Ed. Brasil, 2009; Leiva, João (org.). Cultura SP: hábitos culturais dos paulistas. São Paulo: Tuva, 2014.
} 
possa nos dar uma resposta. As pessoas com deficiência podem tê-la de maneira congênita ou adquirida por meio de alguma eventualidade de saúde, e são vistas como vítimas de determinadas condições alheias a sua vontade, o que oculta uma dose de perversidade ao retirar delas sua autonomia e a possibilidade de serem sujeitos de suas vidas. Já as pessoas em situação de vulnerabilidade social, em piores condições socioeconômicas, tendem a ser vistas como responsáveis por sua situação, especialmente em sistemas nos quais a meritocracia é inquestionável, como se elas não tivessem o valor suficiente para enfrentar e superar suas adversidades. Uma conclusão previsível é "não são vítimas, portanto não merecem nossa assistência", o que também implica uma concepção assistencialista do que seja a acessibilidade, ao invés de considerá-la um direito comum a todos. Sem absolutamente negar a importância de tais ações, essa compreensão torna alguns projetos de acessibilidade mais "palatáveis", como aqueles desenvolvidos com crianças, pessoas de 60 anos ou mais, pacientes de hospitais ou pessoas com deficiência.

Junte-se a isso o fato de os museus serem instituições historicamente ligadas às classes dominantes, e a consequente construção de códigos, procedimentos e símbolos que transmitem uma mensagem de distinção social que acaba por afastar as pessoas que não se sentem participantes de seu universo sociocultural. Assim, as instituições se autossustentam numa redoma de exceção em que seus atores e interlocutores - funcionários e visitantes compartilham do mesmo capital cultural. Dessa forma, os processos de exclusão se dão nas duas direções, de dentro para fora e no sentido inverso.

Em minha prática profissional, percebo que os obstáculos de caráter simbólico aos museus são tão ou mais importantes do que aqueles de ordem material. Em pesquisa sobre percepções da população brasileira a respeito da cultura, realizada pelo Ipea (Instituto de Pesquisa Econômica Aplicada) em 2010 com abrangência nacional, aponta-se que 56\% dos entrevistados indicaram como obstáculo ao acesso aos espaços culturais a barreira social imposta pelo perfil do público que já frequenta esses locais, ou seja, a percepção de que essas instituições não são para eles e seus pares (IPEA, 2010, p. 9). Se contrastamos essa percepção com os dados das pesquisas de perfil de público de museus feitas no âmbito institucional, regional e nacional, vemos que ela não está equivocada. ${ }^{5}$

\footnotetext{
${ }^{5}$ Em 2007, o Núcleo de Ação Educativa da Pinacoteca de São Paulo realizou uma pesquisa qualitativa chamada "Expectativas e percepções em relação à Pinacoteca" [texto não publicado], na qual entrevistou frequentadores do entorno próximo do museu a fim de entender sua relação com a instituição. Entre os diversos pontos levantados reitera-se o desconhecimento sobre as atribuições da Pinacoteca e a percepção de uma pretensa distinção e excepcionalidade, com respondentes mencionando que para acessar o prédio deveriam ser sócios, ou imaginando que o valor de entrada fosse mais caro do que é na realidade.
} 
Como afirma a pesquisadora Maria Vlachou a respeito do desenvolvimento de públicos diversificados,

\begin{abstract}
as barreiras de acesso aos museus não são práticas; elas são mentais e psicológicas, resultado da falta de experiência prévia, conhecimento e práticas. [...] Nosso objetivo é criar as condições para que as pessoas experimentem: inspirando curiosidade, apresentando relevância, tornando os museus de alguma maneira tangíveis, promovendo conforto e bem-estar (principalmente psicológico), construindo pontes. Em muitos casos, teremos que abrir portas; não apenas para que os públicos entrem, mas também para sairmos, abandonarmos nossa zona de conforto e encontrá-los.

(VLACHOU, 2013, p. 84-85, tradução minha)
\end{abstract}

\title{
Diferentes pontos de vista sobre a acessibilidade em museus
}

A partir das reflexões e questionamentos desenvolvidos até aqui, mais do que buscar uma definição unívoca sobre a acessibilidade nas instituições museológicas, vou me dedicar a seguir a um levantamento de definições diferentes e complementares, com base em enfoques, públicos-alvo e autores diversos, buscando perceber as similaridades e particularidades das versões sobre o mesmo termo.

Iniciaremos com referências de pesquisadoras e profissionais que se dedicam ao tema sob o prisma das necessidades de acesso aos museus para as pessoas com deficiência, aspecto que merece maior atenção dos autores no Brasil. Nesse sentido, muitas das discussões partem das questões de acessibilidade física, considerando os obstáculos relativos à mobilidade. Essa vertente encontra-se alicerçada em documentos oficiais e na própria legislação, como podemos ver na definição de acessibilidade do Decreto Federal 5.296, de 2004, que estabelece normas e critérios básicos para a promoção da acessibilidade das pessoas com deficiência, assim definida em seu artigo $8^{\circ}$ :

Condição para utilização, com segurança e autonomia, total ou assistida, dos espaços, mobiliários e equipamentos urbanos, das edificações, dos serviços de transporte e dos dispositivos, sistemas e meios de comunicação e informação, por pessoa portadora de deficiência ou com mobilidade reduzida. (BRASIL, 2004)

Ou, como define a "Norma Brasileira de Acessibilidade a Edificações, Mobiliário, Espaços e Equipamentos Urbanos" da Associação Brasileira de Normas Técnicas (ABNT), é "a possibilidade e condição de alcance, percepção e entendimento para utilização com segurança e autonomia de edificações, espaço, mobiliário, equipamento urbano e elementos" (COHEN; DUARTE; BRASILEIRO, 2012, p. 39). Aqui podemos ver refletida a concepção atualizada da deficiência, na qual a responsabilidade pela eliminação e superação das barreiras e obstáculos é atribuída à sociedade e não mais às próprias pessoas com deficiência. A 


\section{Revista Docência e Cibercultura}

deficiência é assim entendida como resultado da interação entre as pessoas com deficiência e as barreiras sociais impostas pelas atitudes e pelo ambiente que dificultam a igualdade de oportunidades a elas (CONVENÇÃO SOBRE OS DIREITOS DAS PESSOAS COM DEFICIÊNCIA, 2007, Preâmbulo). Com isso, a proposta de desenho universal ou acessibilidade universal ganha força, ao indicar a concepção de ambientes, produtos e serviços que possam ser acessados por todos, sem necessidade de adaptações (ibidem, Definições).

Outro aspecto determinante para a compreensão da acessibilidade para pessoas com deficiência, o qual se desdobra da acessibilidade física, é o acesso sensorial. Esse talvez seja o elemento que mais particularize a acessibilidade para os indivíduos com esse perfil. Se elencarmos os diversos obstáculos ao acesso aos museus, veremos que a acessibilidade sensorial, ainda que possa beneficiar a todos, é indispensável para que pessoas com determinadas deficiências se aproximem dos objetos culturais.

Podemos assim caracterizar o acesso às instituições culturais em seus aspectos físicos (relativos à possibilidade de mobilidade e circulação); em seus aspectos intelectuais (relativos à compreensão de objetos e discursos expositivos, da organização conceitual e linguagem utilizada, das regras institucionais e da orientação espacial); em seus aspectos atitudinais ou emocionais (relativos ao sentimento de acolhimento pela instituição, confiança e prazer pela participação e identificação com os sistemas de produção cultural); em seus aspectos culturais (no que diz respeito ao reconhecimento da diversidade cultural presente na instituição); em seus aspectos financeiros (com a liberação dos valores de entrada) e, por fim, em seus aspectos sensoriais (relativos à possibilidade de acessar os objetos culturais por meio de outros sentidos além da visão e audição, para pessoas com deficiências visuais e auditivas) (MINEIRO, 2004, p. 28-30; AIDAR, 2018, p. 43-44).

Como já mencionamos, todos os visitantes se beneficiam das diferentes possibilidades de acesso acima elencadas, que abrangem desde questões de caráter material e tangível (como as físicas), até outras tão importantes quanto elas, mas de caráter mais imaterial e subjetivo, como são os aspectos intelectuais, atitudinais/emocionais e culturais. Conseguir entrar fisicamente num museu não garante a compreensão de suas exposições e narrativas curatoriais, assim como relacionar-se intelectualmente com o que se observa não é garantia de sentir-se à vontade no museu, nem pertencente a seu ambiente e universo cultural (AIDAR, 2018). Mais uma vez, as barreiras simbólicas e intangíveis são fundamentais para a acessibilidade e têm influência decisiva nos processos educativos, já que o bem-estar (ou mal-estar) emocional impacta diretamente a qualidade dos processos de aprendizagem.

É relevante mencionar que, ainda que separemos e classifiquemos as diferentes instâncias de acesso aos museus, na prática elas tendem a sobrepor-se, complementar-se ou 


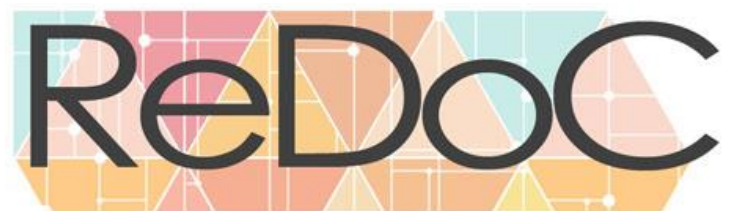

\title{
Revista Docência e Cibercultura
}

serem simultâneas, daí que não há uma hierarquia entre elas, nem tampouco é possível imaginar que a eliminação dos obstáculos físicos às nossas instituições garantirá sua acessibilidade. Ou seja, não serão rampas, elevadores ou banheiros para cadeirantes que nos tornarão verdadeiramente acessíveis, nem mesmo apenas às pessoas com deficiência.

Retomando a questão do acesso sensorial, a discussão recai sobre a necessidade de explorar mais intensamente nos museus a multissensorialidade, o que também beneficiaria a todos, uma vez que nossa experiência vital é sinestésica - não se resume ao uso de um sentido em cada momento, mas utiliza constantemente todos eles em articulação. A preponderância da visão nos museus é empobrecedora para a experiência da visita de todos. Conforme afirmam as autoras dos "Cadernos Museológicos" do Instituto Brasileiro de Museus (IBRAM) relativos à acessibilidade,

\begin{abstract}
Assumir o compromisso com a democratização da cultura significa também pensar em uma multidisciplinaridade na qual a questão da acessibilidade deve estar necessariamente inserida. Trata-se de garantir um direito e, no caso das pessoas com deficiência, uma percepção ambiental que envolve o TER ACESSO, o PERCORRER, o VER, o OUVIR, o TOCAR e o SENTIR os bens culturais produzidos pela sociedade através dos tempos e disponibilizados para toda a comunidade. (COHEN; DUARTE; BRASILEIRO, 2012, p. 22)
\end{abstract}

Isso pode ser desenvolvido por meio de recursos expográficos ou educativos, como maquetes táteis, relevos de imagens bidimensionais disponíveis para o toque, sonorização de exposições, elementos olfativos para serem associados a objetos ou obras de arte, objetos originais disponíveis ao toque e recursos de tecnologia assistiva como audioguias e videoguias, entre outros. ${ }^{6}$

Outro aspecto comum a diversas definições de acessibilidade tem a ver com sua correspondência com o exercício dos direitos humanos ou culturais, especialmente aquelas que se baseiam nos documentos internacionais para sua concepção, tal como a desenvolvida pelo Ministério da Cultura da Argentina em sua Guía Práctica de Accesibilidad Cultural:

Accesibilidad cultural implica brindar iguales condiciones de participación a todas las personas que forman parte de una sociedad determinada, que por alguna razón física o cognitiva se ven imposibilitadas para el pleno disfrute de sus derechos, teniendo en cuenta las barreras provocadas por las actitudes y por el ambiente que los rodea. (ARGENTINA, 2018, p. 8)

\footnotetext{
${ }^{6}$ Uma série de instituições culturais desenvolvem tais recursos, entre as quais podemos mencionar os recursos de apoio multissensoriais desenvolvidos e utilizados pelo Programa Educativo para Públicos Especiais da Pinacoteca, que elaborou recursos para aproximadamente 60 obras de arte do acervo do museu por meio de elementos e materiais táteis, sonoros, olfativos e visuais.
} 
Segundo o mesmo guia, existem quatro eixos simultâneos a serem trabalhados para que os produtos culturais alcancem distintos tipos de acessibilidade para pessoas com deficiência: a infraestrutura, a fim de garantir a autonomia na mobilidade, a adaptação na comunicação e no conteúdo e a capacitação dos recursos humanos da área cultural (ARGENTINA, 2018, p. 11-14). Alguns autores vão além, ao advogar que uma política institucional de acessibilidade deve contemplar não apenas a capacitação dos trabalhadores e a consultoria de pessoas com deficiência no desenvolvimento das ações, mas a contratação de profissionais com deficiência em suas equipes, especialmente para funções que tenham interface direta com o público (TOJAL, 2015, p. 201).

Além disso, ao se comprometer com a criação de uma política institucional de acessibilidade, a transversalidade das ações e o envolvimento de todos os profissionais e áreas são imprescindíveis, evitando a tão comum responsabilização (interna e externa) de determinadas áreas, como as educativas. De acordo com Tojal,

\begin{abstract}
a conclusão que se impõe é de que pouco ou nada adiantarão iniciativas isoladas de inclusão e propostas de acessibilidade nos espaços expositivos se não houver de verdade uma política de inclusão que assuma esse conceito de forma permanente e que venha a plasmar todas as áreas da instituição, abrangendo não somente a área educativa, mas também as áreas de pesquisa, documentação, conservação e comunicação, além de todos os profissionais envolvidos com a recepção, segurança e o atendimento aos públicos do museu. (TOJAL, 2015, p. 195)
\end{abstract}

A acessibilidade em um museu não depende da boa vontade e empenho de uma pessoa ou equipe particular, mas de respaldo em políticas públicas e de um desejo e compromisso de sua gestão institucional.

Mesmo entre os autores que se dedicam mais detidamente às questões da acessibilidade voltada às pessoas com deficiência, há uma compreensão geral de que esse é um conceito que deve ser trabalhado de maneira mais abrangente (ou menos excludente, se quisermos), reconhecendo que os grupos com dificuldades de acesso aos museus são mais ampliados. Seja porque as diferentes e complementares possibilidades de promoção do acesso beneficiem potencialmente a todos, ou porque o entendimento atual do trabalho com pessoas com deficiência pressuponha uma maior integração entre esses coletivos e as pessoas sem deficiência, o que dentro da área da educação inclusiva é chamado genericamente de inclusão (ações para grupos de pessoas com e sem deficiência juntos), tal abordagem ganha força atualmente (COHEN; DUARTE; BRASILEIRO, 2012, p. 40; TOJAL, 2015, p. 197). Nesse sentido, as ideias da equiparação de oportunidades e da acessibilidade universal se articulam numa proposição que favoreça a todos, independentemente de suas capacidades ou habilidades. Conforme afirma Vlachou, 
Persiste a ideia de que tudo se pode tornar acessível porque estamos disponíveis para dar uma "ajudinha" a quem precisa subir e descer numa cadeira de rodas ou a quem pede uma “explicação". Mas o objetivo não é esse. O objetivo é proporcionar a todas as pessoas igualdade nas condições de acesso, respeitando a sua vontade e os seus interesses, tomando em consideração as suas capacidades e garantindo a sua autonomia. (VLACHOU, 2017, p. 47)

Outras definições do termo abraçam essa ideia de forma ainda mais abrangente, ao não mencionarem públicos-alvo específicos. É o caso, por exemplo, do verbete sobre acessibilidade elaborado no âmbito do Comitê Educativo da Unidade de Preservação do Patrimônio Museológico, da Secretaria da Cultura do Estado de São Paulo (UPPM/SEC). Esse comitê congrega profissionais das áreas educativas das 19 instituições museológicas estaduais, que se encontram mensalmente para debater questões da área. ${ }^{7}$ Ao longo dos anos, o comitê se organizou em diferentes grupos de trabalho (GTs) para aprofundar alguns temas, entre eles um GT sobre conceitos da educação museal. Inicialmente criado para definir conceitos que pudessem ter um entendimento comum entre os participantes do Comitê, a partir de 2016 o GT procedeu ao levantamento de conceitos-chave referenciais utilizados pelas áreas educativas de cada museu participante, a fim de levantar os mais recorrentes. Entre eles estavam patrimônio, identidade, experiência, ludicidade e acessibilidade. A construção coletiva de cada verbete envolveu dinâmicas, redação em grupos e uma construção final pelo GT, validada pelo grupo ampliado em outubro de 2018. Segundo o grupo do Comitê Educativo da UPPM/SEC,

A acessibilidade em museus abrange a promoção do acesso físico, comunicacional, intelectual, atitudinal e social, ao considerar a alteridade e valorizar a diversidade, a fim de garantir a participação social e cultural. Ações que promovam a acessibilidade devem respeitar e estimular a autonomia dos sujeitos e grupos, ao propiciar oportunidades de fruição e criação com independência e equidade.

Outras definições possuem caráter mais poético e projetivo, ao incluir em seu escopo o que se imagina ser o objetivo da promoção do acesso, tal como formulado pela equipe do educativo do Museu de Arte Moderna de São Paulo, quando afirma que "acessibilidade, para nós no MAM, não é apenas promover acesso ao que já existe, mas, sim, pensar e construir a realidade que se deseja viver" (LEYTON, 2018, p. 25).

Podemos ainda mencionar a tendência em tratar o tema do ponto de vista das desigualdades sociais, em particular daquelas de caráter socioeconômico. Esse olhar para a acessibilidade dialoga diretamente com a realidade brasileira e as pesquisas de público da

\footnotetext{
${ }^{7}$ As instituições participantes são: Museu Afro Brasil, Museu de Arte Sacra, Museu Casa de Portinari, Museu da Casa Brasileira, Museu Catavento, Museu do Café, Museu da Diversidade Sexual, Museu Felícia Leirner, Museu do Futebol, Museu Histórico e Pedagógico Índia Vanuíre, Museu da Imigração, Museu da Imagem e do Som de São Paulo, Museu da Língua Portuguesa, Pinacoteca de São Paulo, Memorial da Resistência de São Paulo, Casa das Rosas, Casa Guilherme de Almeida, Casa Mário de Andrade e Paço das Artes.
} 


\section{Revista Docência e Cibercultura}

cultura e dos museus no país, que indicam como principal corte que limita o acesso às instituições os níveis de renda e escolaridade dos indivíduos (CHIOVATTO; AIDAR; SOARES; AMARO, 2010, p. 18-19). Essa é também uma percepção transversal da acessibilidade, uma vez que outros aspectos que dificultam o acesso, tais como a faixa etária ou o fato de serem pessoas com deficiência, podem ser influenciados pela renda e capital cultural familiar. Em outras palavras, um idoso ou pessoa com deficiência de uma família de alta renda e escolaridade tem maior chance de acesso às instituições culturais e às oportunidades socioeducativas de modo geral.

Como afirmam Chagas e Storino,

Assim como é indispensável superar as barreiras físicas, sensoriais e cognitivas que impedem o pleno acesso aos museus e ao patrimônio, também é preciso vencer as barreiras econômicas, sociais e culturais e enfrentar o desafio de ampliar radicalmente o acesso aos seus serviços e produtos. Em outras palavras: é preciso vencer as barreiras imateriais que enquadram os museus num estilo de vida das elites, fora do alcance das camadas populares. (CHAGAS; STORINO, 2012, p. XIV)

Aqui, podemos retomar a discussão já apontada anteriormente sobre a inclusão social nos museus e sobre um preconceito de classe latente e não assumido com relação às classes populares por parte das instituições, quando do desenvolvimento de suas políticas ou projetos de inclusão e acessibilidade.

\section{Alguns exemplos da acessibilidade em museus}

Conscientes dessa problemática, diversos museus vêm desenvolvendo ações de acessibilidade para uma variedade de públicos, em particular aqueles reconhecidamente não frequentadores. A título de exemplo, mencionarei processos desenvolvidos em três instituições, uma no país e duas no exterior. O primeiro deles se refere a duas experiências promovidas recentemente pelo Museo Nacional de Colombia, em Bogotá. Uma delas trata da nova proposta curatorial de um dos núcleos da exposição de longa duração do museu, chamado "Tiempo sin olvido: diálogos desde el mundo prehispánico" (ou "Tempo sem esquecimento: diálogos desde o mundo pré-colonial"). A exposição, apesar de sua temática, não se detém apenas em objetos arqueológicos ou etnológicos, mas abrange também históricos e artísticos, e seu partido curatorial se desenvolve em torno de dez eixos temáticos que enfatizam traços particulares do comportamento humano: produzir, habitar, trabalhar, tecer, trocar, representar, controlar, lutar, celebrar e morrer (MUSEO NACIONAL DE COLOMBIA, s. d.). Para cada módulo da exposição foram elaboradas réplicas de objetos expostos, feitas nos mesmo materiais dos originais, disponíveis para a percepção visual e tátil de todos os visitantes. Essas réplicas, em 


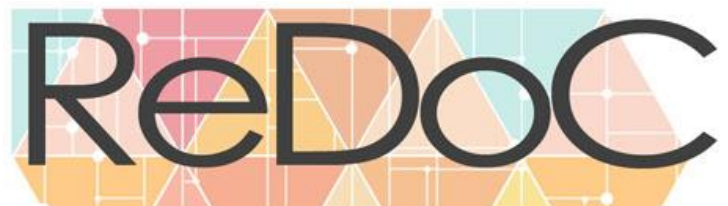

\section{Revista Docência e Cibercultura}

sua maioria de objetos cerâmicos, são acompanhadas de etiquetas indicando que podem ser tocadas para a exploração de suas formas e materiais. Também as acompanham perguntas de ordem investigativa e interpretativa, como no caso do módulo "Producir: el lugar de los alimentos" ("Produzir: o lugar dos alimentos"), em que se pergunta numa etiqueta: "De onde provêm os alimentos que você consome? Quais deles têm a origem mais longínqua?”. Uma interessante abordagem de acessibilidade, ao propor, a todos os visitantes, desde uma possibilidade de acesso sensorial, até uma de ordem intelectual e cultural, aproximando conceitos trabalhados pela mostra do cotidiano do público, na busca de criar empatia com relação aos povos originários.

O segundo exemplo, da mesma instituição, refere-se a outra exposição, uma mostra temporária desenvolvida colaborativamente com um grupo de jovens em situação de vulnerabilidade social de Bogotá. A mostra "Historias de la ' $L$ ': ensamblando un mundo en un modelo a escala" ("Histórias da 'L': construindo um mundo em um modelo em escala") esteve em cartaz durante o segundo semestre de 2018, e seu projeto foi contemplado com o segundo lugar no $9^{\circ}$ Prêmio Ibermuseos de Educação.

A "L" ou a "rua Bronx", localizada no centro de Bogotá, foi durante anos o epicentro do mercado de drogas da cidade, um lugar estigmatizado e violento, mas também espaço de encontro de pessoas de diferentes procedências, idades e origens sociais. Em 2016, a prefeitura desalojou o setor como parte de um programa de segurança pública e renovação urbana. Após a demolição do local, vários jovens que lá viviam foram encaminhados para uma instituição de assistência social. A partir de uma parceria entre o Museo Nacional e essa instituição, sob coordenação da equipe de Curadoria de Etnografia do museu, propôs-se que um grupo de dez jovens montasse um modelo em escala da "L" no próprio espaço expositivo, enquanto dialogavam com os visitantes e especialistas sobre suas experiências. Além da maquete, os jovens também fizeram fotografias dos escombros do local, que junto a etiquetas comentadas formaram parte da exposição. Tanto a definição dos objetivos da mostra como a redação dos textos foram elaboradas entre os jovens e a equipe do museu, num processo de curadoria participativa. A formação em mediação para os jovens e os diálogos com o público foram mediados pela área educativa do museu. No final da exposição, a maquete foi adquirida pelo museu e será levada para uma das novas salas da exposição de longa duração, que atualmente está sendo remodelada. ${ }^{8}$

\footnotetext{
${ }^{8}$ As informações e fotografias do projeto foram gentilmente compartilhadas por Andrés Góngora, Curador Chefe de Etnografia do Museo Nacional de Colombia.
} 


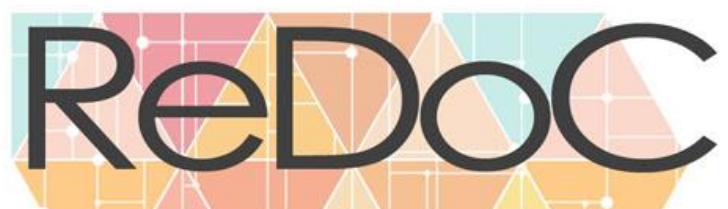

\section{Revista Docência e Cibercultura}

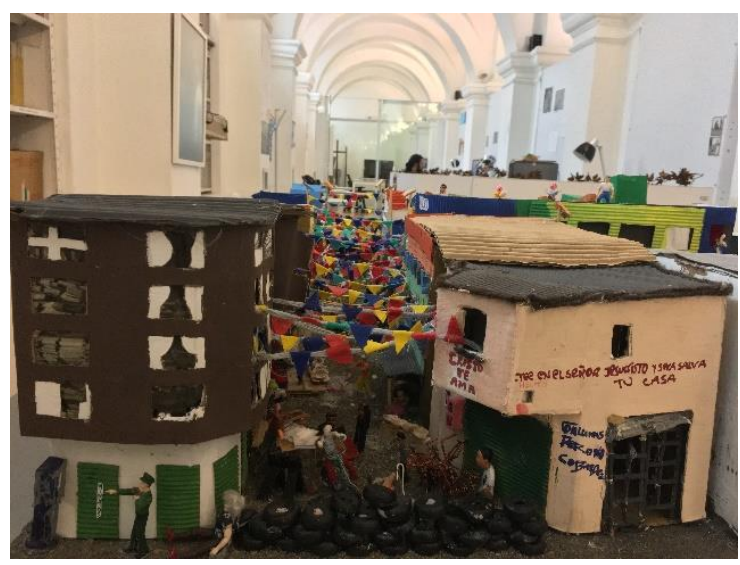

Figura 1. Maquete da "L" construída pelos jovens no espaço expositivo do Museo Nacional de Colombia.

Fonte: Museo Nacional de Colombia.

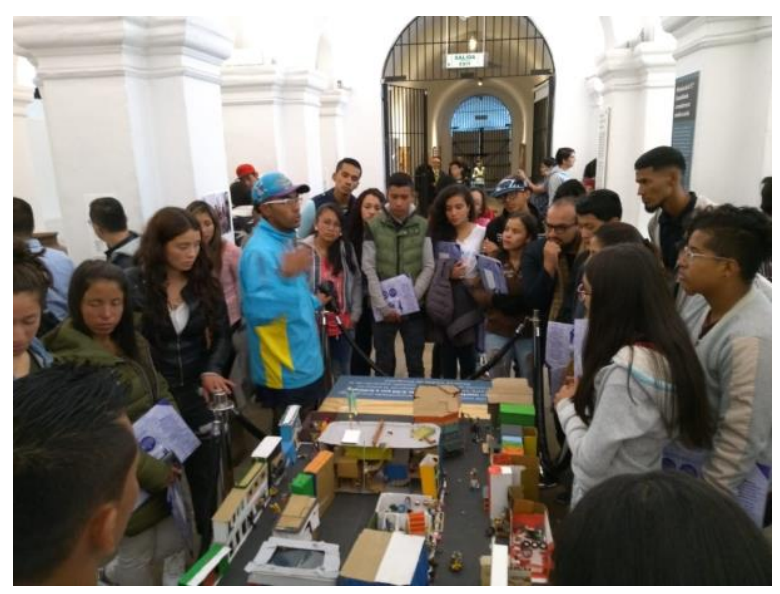

Figura 2. Jovem participante do projeto apresenta a maquete e aborda suas experiências de vida no local a grupo de visitantes do museu. Fonte: Museo Nacional de Colombia.

Essa experiência é exemplar por diversos motivos, entre eles o fato de trabalhar com um grupo socialmente marginalizado; propiciar autonomia criativa aos seus membros e protagonismo ao exporem sua voz e pontos de vista; visibilizar sua produção dentro de um museu nacional, com toda a carga de oficialidade que isso implica; reconhecer e valorizar histórias tidas como marginais e incorporar o conflito, ao não se intimidar em expor uma situação politicamente delicada, exibindo a arbitrariedade do poder público em desalojar uma área ocupada por grupos vulneráveis. Além disso, as duas experiências do Museo Nacional de Colombia são significativas por serem propostas e conduzidas por equipes curatoriais, contando 


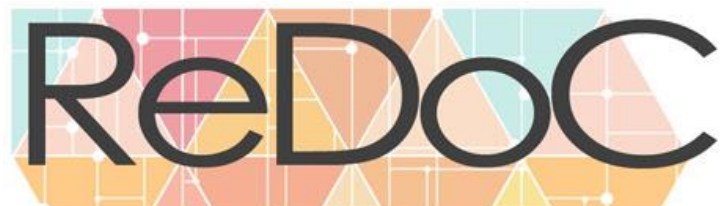

\section{Revista Docência e Cibercultura}

com a participação das áreas educativas. O mais usual quando do desenvolvimento de projetos de acessibilidade nos museus é que eles sejam elaborados justamente pelas equipes educativas, como veremos nos exemplos a seguir.

O segundo exemplo trata dos programas e projetos educativos desenvolvidos pelo Montreal Museum of Fine Arts, nessa mesma cidade, no Canadá. A área de educação do museu se autointitula "Education and Art Therapy" ("Educação e Arte Terapia"), o que já indica outra abordagem com relação aos seus programas educativos, numa articulação estreita entre arte, educação e saúde. A área se divide entre o que chamam de "Educação", com ações voltadas principalmente a estudantes e professores, e outros dois núcleos chamados de "Arte terapia e bem-estar" e "Acessibilidade e inclusão", com ações junto a grupos de pessoas com deficiência e seus familiares, com distúrbios alimentares, com transtornos mentais, imigrantes, grupos indígenas, crianças e famílias em situação de vulnerabilidade social, crianças e jovens de famílias multiétnicas, grupos intergeracionais, mulheres imigrantes, mães solteiras, jovens de comunidades afro-canadenses e muçulmanas, pessoas em situação de rua, pessoas analfabetas ou de baixa escolaridade e jovens vítimas de violência. Cada um desses coletivos participa das ações do museu por meio de parcerias e projetos específicos, sem os quais muitos deles dificilmente teriam contato com uma instituição museológica.

O último núcleo do educativo do museu canadense se chama "Atividades culturais" e se organiza em ações para grupos divididos em faixas etárias, como adultos, crianças e famílias, idosos ou com ações de educação museal para outras organizações, e o que chamam de EducExpo, com exposições de caráter educativo, como as mais recentes, uma delas sobre os deficits educacionais de meninas da África subsaariana (intitulada "When I Grow up, I'm Going to Be... Toward an Inclusive Education for Girls Around the World", em português "Quando eu crescer, Eu quero ser... Rumo a uma Educação Inclusiva para Meninas em Todo o Mundo"), e uma exposição de arte feita com grupos comunitários da cidade, tendo por foco a criação artística como veículo de coesão social ("What If...? Diversity, Togetherness, Inclusion and Artistic Expression to Strengthen Social Bonds", "E Se...? Diversidade, União, Inclusão e Expressão Artística para Fortalecer os Laços Sociais") (MONTREAL MUSEUM OF FINE ARTS, s. d.).

Para finalizar os exemplos, mencionarei os programas dos quais participo na Área de Ação Educativa da Pinacoteca de São Paulo, os quais chamamos de Programas Educativos Inclusivos, voltados a públicos não tradicionalmente visitantes e para os quais temos de desenvolver ações mais proativas de aproximação. Nesse caso, são programas que atuam com pessoas com deficiências físicas, sensoriais e intelectuais, ou com transtornos mentais; com grupos de pessoas em situação de vulnerabilidade social, muitos do próprio entorno do museu; 


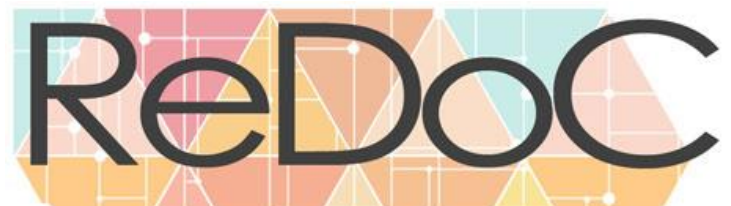

\section{Revista Docência e Cibercultura}

com pessoas com 60 anos ou mais, e também com a formação continuada dos funcionários do museu, especialmente das áreas de recepção e de equipes terceirizadas de segurança e limpeza.

A opção por trabalhar com esses perfis de públicos se deve em parte a um diálogo com nosso contexto institucional, como no caso dos idosos, grupo etário sub-representado nas pesquisas de perfil de público espontâneo do museu. No caso dos grupos em situação de vulnerabilidade social, com os quais trabalhamos por meio do Programa de Inclusão Sociocultural, são em sua maioria da região central da cidade, onde a Pinacoteca se localiza, ou seja, são nossos vizinhos. Nesse caso, compõem-se em grande parte de grupos de adultos em situação de rua, além de pessoas que fazem uso problemático de drogas.

Apesar de termos equipes e abordagens educativas específicas em cada um desses quatro programas, eles possuem pressupostos metodológicos comuns. O primeiro deles é o desenvolvimento de ações a partir dos perfis, repertórios, experiências, interesses e demandas dos grupos, ou seja, implica a elaboração de percursos singulares para cada grupo, em oposição à ideia de roteiros educativos predeterminados, relativamente comum na educação museal. $\mathrm{O}$ contato com os públicos-alvo se dá por meio do estabelecimento de parcerias com organizações, projetos e coletivos com os quais estejam vinculados. Entre as organizações parceiras encontram-se desde aquelas de caráter mais institucionalizado, como organizações de educação não formal, de assistência social ou de saúde, até movimentos sociais. São essas parceiras que garantirão a continuidade dos processos educativos desenvolvidos. Os programas atuam prioritariamente de maneira continuada com os educandos, o que permite $o$ aprofundamento das estratégias e das relações e vínculos com os grupos e entre eles. Isso possibilita que os próprios educandos definam o que será interessante no contato com o museu, dada sua maturidade e familiaridade com a Pinacoteca e as demandas advindas disso.

Outra ação comum são os cursos de formação para profissionais que atuam com os públicos-alvo, em sua maioria profissionais da assistência social, saúde ou educação inclusiva. São formações com carga horária extensa, entre 40 e 60 horas/aula, que têm como objetivo compartilhar subsídios para que os profissionais utilizem os museus e outros equipamentos culturais em suas práticas socioeducativas, apropriando-se dos espaços, conteúdos e procedimentos da Pinacoteca e dos museus em geral.

Por fim, vale mencionar que assim como em todo processo de educação museal, mas talvez mais intensamente com grupos com dificuldades de acesso, os resultados das ações podem envolver desde a aquisição de conhecimentos formais e a ampliação de repertórios, até aspectos mais subjetivos, como aqueles relacionados à melhoria da sociabilidade e das habilidades de comunicação; ao fortalecimento de identidades; à criação de vínculos com o museu, entre os membros do grupo e com os outros visitantes; à promoção de bem-estar e à 


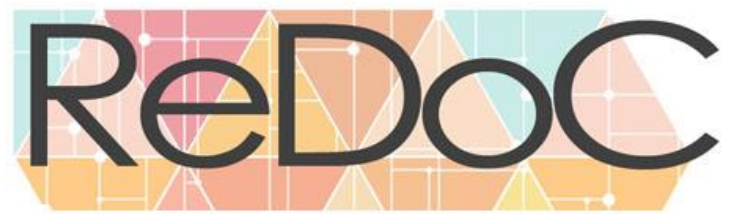

\title{
Revista Docência e Cibercultura
}

melhoria da autopercepção e da autoafirmação dos indivíduos e grupos envolvidos (CHIOVATTO; AIDAR; SOARES; AMARO, 2010, p. 20).

\section{Problematizações finais}

Para finalizar as reflexões propostas neste artigo, que não se pretendem conclusivas sob nenhum aspecto, parece ainda relevante apontar alguns questionamentos e indicações de desdobramentos que os conceitos de acesso e acessibilidade recebem, quando vistos de certa perspectiva.

O primeiro deles tem a ver com o que estamos tornando acessível dentro de nossas instituições, numa discussão que remete à ideia de democratização da cultura, como se desenvolver políticas de acessibilidade acriticamente fosse assumir uma postura de doutrinação cultural, na qual estimulamos o consumo cultural de grupos não frequentadores a fim de popularizar a cultura erudita e dominante dos museus, vista como necessária a toda a população. Ainda que em alguns casos possamos reconhecer ações de acessibilidade que partam dessa premissa, não podemos circunscrever todas elas dentro desses parâmetros e intencionalidades, como já pudemos perceber em alguns pontos e exemplos aqui compartilhados.

De acordo com Vlachou,

\begin{abstract}
há muitos de nós que defendem o "acesso", mas o acesso ao que definimos como cultura válida. Ainda assim, e se tentássemos conhecer melhor as comunidades nas quais estamos inseridos? E se abríssemos nossos espaços (que também são delas), envolvendo-as, criando conforto (físico, psicológico e intelectual) e sentimento de pertencimento? E se programássemos junto com elas? E se os artistas fossem elas? (VLACHOU, 2013, p. 92, tradução minha)
\end{abstract}

Aqui tocamos na questão da democracia cultural, em seu sentido de não hierarquizar as manifestações da cultura e dar acesso mais à produção cultural do que ao seu consumo, favorecendo a participação dos públicos não apenas como espectadores, mas como agentes ativos (TEIXEIRA LOPES, 2009). Ainda citando a mesma autora,

Trabalhar com as pessoas não significa "dar às pessoas o que querem" [...] É estarmos sensíveis ao que interessa, preocupa, inquieta, alegra a comunidade que nos envolve, e procurar construir uma programação que nos permite refletir, em conjunto, sobre tudo isso. (VLACHOU, 2017, p. 53) 


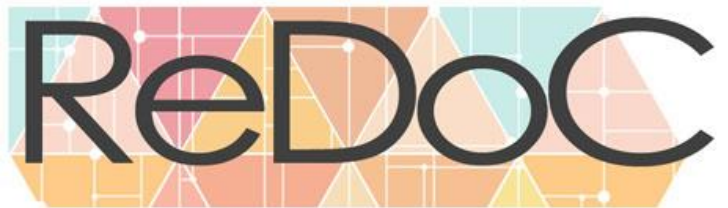

\section{Revista Docência e Cibercultura}

Outros profissionais, ligados particularmente à Museologia Social, encaminham suas reflexões sobre a acessibilidade para um viés complementar a esse. Conforme afirmam Chagas e Storino,

democratizar o acesso aos museus é fundamental, mas é pouco. É preciso compreender o museu como um meio, uma ferramenta, uma máquina, um processo ou um sistema social que deve ser democratizado. Além disso, é importante, do nosso ponto de vista, estimular e contribuir para a relação direta das comunidades populares com os museus, compreendendo que no âmbito dessa relação há espaço para instalarse o inesperado, o novo, o ovo do dragão. (CHAGAS; STORINO, 2012, p. XIV)

Para essa linha de pensamento, proporcionar acesso ao museu tradicional e construído sobre bases elitistas não seria produtivo ou suficiente, mas sim, que os coletivos pudessem adquirir os "meios de produção" do fazer museológico, criando instituições renovadas a partir da elaboração e legitimação de outros códigos culturais, advindos de grupos sociais menos privilegiados, por meio, por exemplo, da criação de experiências museológicas comunitárias.

Ainda que essas proposições sejam bastante estimulantes para quem acredita na emergência de novas experiências museais, elas nos colocam diante de um impasse: como as instituições mais tradicionais podem participar desses processos? Ou elas devem ser esquecidas e seguir servindo apenas às classes dominantes?

Respaldada em minha experiência, acredito que o que os museus tradicionais têm a compartilhar, ainda que dentro de suas limitações institucionais e históricas, pode ser potencialmente relevante a todos, a depender da abordagem, da qualidade do contato com o patrimônio e com a instituição, e das relações resultantes. Além disso, a contradição pode instalar-se desde dentro, por meio do questionamento dos discursos oficiais.

\section{Conforme afirma Encarna Lago,}

Não se trata de adquirir ou incorporar públicos, antes excluídos e agora potenciais, mas de sermos lugares de criação onde comunitariamente passemos de espectadores a pensadores, criadores e gestores da iniciativa. Evidentemente, isso pressupõe enfrentar riscos, dialogar com os outros, criar linguagens comuns e acessíveis, sair à rua para observar a expressão artística que aí sucede, repensar os espaços para que nasçam as iniciativas criadoras e gerar um patrimônio distinto que, depois, vai ser ou não valorizado, mas que existe por si. (LAGO, s. d., tradução minha)

Nesse sentido, os museus de base comunitária têm mais liberdade e melhores condições de experimentar uma gestão e processos de trabalho acessíveis e colaborativos, mas as possibilidades de participação e interlocução dos públicos com os museus são variadas, e as instituições mais tradicionais podem e devem empreendê-las. A renovação de determinadas 


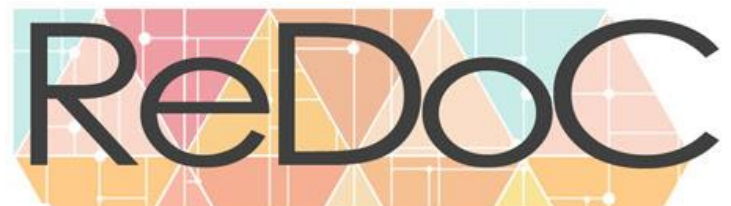

\section{Revista Docência e Cibercultura}

práticas museológicas dentro das instituições tradicionais coloca-se como um desafio a ser enfrentado, e os processos de acessibilidade fazem parte desse esforço.

Para concluir, o que podemos, portanto, depreender de um olhar mais detido sobre as diversas concepções da acessibilidade em museus é que elas necessariamente implicam atenção e respeito para com os outros (visitantes, públicos potenciais ou cogestores de nossas instituições), na disponibilidade para o diálogo e para a construção conjunta, no estabelecimento de relações não hierarquizadas e no compartilhamento do poder, seja ele de classe, institucional ou narrativo.

\section{Referências}

AIDAR, Gabriela. Museus e inclusão social. Ciências \& Letras, Porto Alegre: Faculdade Porto-Alegrense de Educação, Ciências e Letras, n. 31, p. 53-62, 2002.

AIDAR, Gabriela. Ampliando o acesso. In: INSTITUTO TOMIE OHTAKE. Mediações acessíveis: ciclo de encontros sobre acessibilidade em espaços de educação e cultura. São Paulo: Instituto Tomie Ohtake, 2018.

AMERICAN ALLIANCE OF MUSEUMS (AAM). Diversity, Equity, Accessibility and Inclusion. Disponível em: https://www.aam-us.org/category/diversity-equity-inclusionaccessibility/; https://www.aam-us.org/programs/resource-library/diversity-equityaccessibility-and-inclusion-resources/. Acesso em: jan. 2019.

ARGENTINA. Ministerio de Cultura. Presidencia de la Nación Argentina. Guía Práctica de Accesibilidad Cultural. Ministerio de Cultura - Presidencia de la Nación Argentina, Laboratório de Innovación Cultural, 2018.

BRASIL. Presidência da República. Casa Civil - Subchefia para Assuntos Jurídicos. Decreto $n^{0}$ 5.296 de 2 de dezembro de 2004. Regulamenta as Leis nos 10.048 , de 8 de novembro de 2000, que dá prioridade de atendimento às pessoas que especifica, e 10.098, de 19 de dezembro de 2000, que estabelece normas gerais e critérios básicos para a promoção da acessibilidade das pessoas portadoras de deficiência ou com mobilidade reduzida, e dá outras providências. Disponível em: http://www.planalto.gov.br/ccivil_03/_Ato20042006/2004/Decreto/D5296.htm. Acesso em: jan. 2019.

BRASIL. Presidência da República. Casa Civil - Subchefia para Assuntos Jurídicos. Decreto $n^{0}$ 6.949 de 25 de agosto de 2009. Promulga a Convenção Internacional sobre os Direitos das Pessoas com Deficiência e seu Protocolo Facultativo, assinados em Nova York, em 30 de março de 2007. Disponível em: http://www.planalto.gov.br/ccivil_03/_ato20072010/2009/decreto/d6949.htm. Acesso em: jan. 2019. 
CHAGAS, Mário; STORINO, Cláudia. O desafio da acessibilidade aos museus (Prefácio). In: COHEN, Regina; DUARTE, Cristiane Rose; BRASILEIRO, Alice. Acessibilidade a museus. Brasília: MinC/IBRAM, 2012. (Cadernos Museológicos, v. 2).

CHIOVATTO, Milene; AIDAR, Gabriela; SOARES, Luis Roberto; AMARO, Danielle. Repensando a acessibilidade em museus: a experiência do Núcleo de Ação Educativa da Pinacoteca do Estado de São Paulo. In: SANTOS, Anderson (org.). Diálogos entre Arte e Público: acessibilidade cultural: o que é acessível e para quem? Recife: Fundação de Cultura Cidade do Recife, 2010. Caderno de textos III, p. 18-21.

COHEN, Regina; DUARTE, Cristiane Rose; BRASILEIRO, Alice. Acessibilidade a museus. Brasília: MinC/IBRAM, 2012. (Cadernos Museológicos, v. 2).

INSTITUTO DE PESQUISA ECONÔMICA APLICADA (IPEA). Sistema de Indicadores de Percepção Social - Cultura. Brasília: IPEA, 2010.

LAGO, Encarna. Un museo, ou é social ou non é museo. S. d. Disponível em: http://praza.gal/cultura/un-museo-ou-e-social-ou-non-e-museo. Acesso em: jan. 2019.

LEIVA, João; MEIRELLES, Ricardo (org.). Cultura nas capitais: como 33 milhões de brasileiros consomem diversão e arte. Rio de Janeiro: 17street, 2018.

LEYTON, Daina. Visitas mediadas + experiências poéticas. In: MUSEU DE ARTE MODERNA DE SÃO PAULO. Educação e acessibilidade: experiências do Museu de Arte Moderna de São Paulo. São Paulo: Museu de Arte Moderna de São Paulo, 2018.

MINEIRO, Clara (coord.). Coleção Temas de Museologia - Museus e acessibilidade. Lisboa: Instituto Português de Museus, 2004.

MONACO, Giuseppe (ed.). Museum Education and Accessibility: bridging the gaps. Proceedings of the 46th Annual ICOM-CECA Conference (2015). Washington (USA): ICOM/CECA, 2016.

MONTREAL MUSEUM OF FINE ARTS. S. d. Disponível em: https://www.mbam.qc.ca/en/. Acesso em: jan. 2019.

MUSEO NACIONAL DE COLOMBIA. S. d. Disponível em: http://www.museonacional.gov.co/exposiciones/permanentes/Paginas/Primer_piso/3.aspx. Acesso em: jan. 2019.

OLIVEIRA, Margarete. Cultura e inclusão na educação em museus: processos de formação em mediação para educadores surdos. 2015. Dissertação (Mestrado em Museologia) - Programa de Pós-Graduação Interunidades em Museologia, Universidade de São Paulo (USP). São Paulo, 2015. 


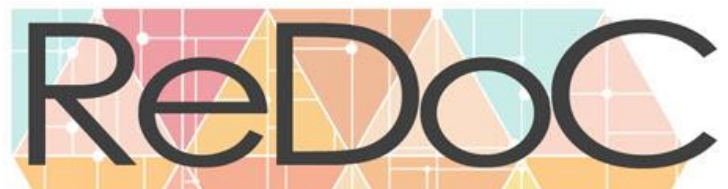

\section{Revista Docência e Cibercultura}

O'NEILL, Mark. The good enough visitor. In: SANDELL, Richard (ed.). Museums, society, inequality. London: Routledge, 2002.

ORGANIZAÇÃO DAS NAÇÕES UNIDAS PARA A EDUCAÇÃO, A CIÊNCIA E A CULTURA (UNESCO). Declaracion de Salamanca y Marco de Accion para las

Necesidades Educativas Especiales. 1994. Disponível em:

https://unesdoc.unesco.org/search/N-EXPLORE-d90eea79-66c8-4aab-be99-d6addd3683bb.

Acesso em: jan. 2019.

SESC-SP. Atitudes acessíveis pra você, pra mim, pra todos nós... São Paulo: SESC-SP, 2018.

TEIXEIRA LOPES, João. Da democratização da Cultura a um conceito e prática alternativos de Democracia Cultural. Revista Saber \& Educar, Porto, n. 14, 2009.

TOJAL, Amanda. Política de acessibilidade comunicacional em museus: para quê e para quem?. Revista Museologia e Interdisciplinaridade, Brasília: Universidade de Brasília, v. 4, n. 7, 2015.

VLACHOU, Maria. Acessibilidade e cultura. Conversas de Lisboa. Lisboa: Câmara Municipal de Lisboa/Agenda Cultural de Lisboa, 2017.

VLACHOU, Maria. Musing on culture: management, communications and our relationships with people. Lisbon: Bypass, 2013. 